\title{
Comparison of Oxygen Uptake During and after the Execution of Resistance Exercises and Exercises Performed on Ergometers, Matched for Intensity
}

\author{
by \\ José Vilaça-Alves ${ }^{1,2}$, Nuno Miguel Freitas ${ }^{1}$, Francisco José Saavedra ${ }^{1,2}$, Christopher B. \\ Scott ${ }^{3}$, Victor Machado dos Reis ${ }^{1,2}$, Roberto Simão ${ }^{4}$, Nuno Garrido ${ }^{1,2}$
}

The aim of this study was to compare the values of oxygen uptake $\left(\mathrm{VO}_{2}\right)$ during and after strength training exercises (STe) and ergometer exercises (Ee), matched for intensity and exercise time. Eight men (24 \pm 2.33 years) performed upper and lower body cycling Ee at the individual's ventilatory threshold (VE/VCO $)$. The STe session included half squats and the bench press which were performed with a load at the individual blood lactate concentration of $4 \mathrm{mmol} / \mathrm{l}$. Both sessions lasted 30 minutes, alternating 50 seconds of effort with a 10 second transition time between upper and lower body work. The averaged overall VO2 between sessions was significantly higher for Ee $(24.96 \pm 3.6$ $\left.\mathrm{ml} \cdot \mathrm{kg} \cdot \mathrm{min}^{-1}\right)$ compared to STe $\left(21.66 \pm 1.77 \mathrm{ml} \cdot \mathrm{kg} \cdot \mathrm{min}^{-1}\right)(p=0.035)$, but this difference was only seen for the first 20 minutes of exercise. Absolute VO2 values between sessions did not reveal differences. There were more statistically greater values in Ee compared to STe, regarding $\mathrm{VO}_{2}$ of lower limbs $\left(25.44 \pm 3.84 \mathrm{ml} \cdot \mathrm{kg} \cdot \mathrm{min}^{-1}\right.$ versus $21.83 \pm 2 \cdot 24$ $\left.\mathrm{ml} \cdot \mathrm{kg} \cdot \mathrm{min}^{-1} ; p=0.038\right)$ and upper limbs $\left(24.49 \pm 3.84 \mathrm{ml} \cdot \mathrm{kg} \cdot \mathrm{min}^{-1}\right.$ versus $\left.21.54 \pm 1.77 \mathrm{ml} \cdot \mathrm{kg} \cdot \mathrm{min}^{-1} ; \mathrm{p}=0.047\right)$. There were further significant differences regarding the moment effect $(p<0.0001)$ of both STe and Ee sessions. With respect to the moment $\times$ session effect, only $\mathrm{VO}_{2} 5$ minutes into recovery showed significant differences $(p=0.017)$. In conclusion, although significant increases in $\mathrm{VO}_{2}$ were seen following Ee compared to STe, it appears that the load/intensity, and not the materiallequipment used for the execution of an exercise, are variables that best influence oxygen uptake.

Key words: strength training, ergometer exercises, aerobic exercise, ventilation.

\section{Introduction}

There is consensus in the scientific community on oxygen uptake $\left(\mathrm{VO}_{2}\right)$ rates being higher during, and lower after, the performance of predominantly aerobic exercises when compared with traditional strength training exercises (STe) (Borsheim and Bahr, 2003; Burleson et al., 1998; Drummond et al., 2005; Gillette et al., 1994). However, in most studies, ergometer exercises (Ee) traditionally are used to perform what is known as aerobic-type exercise
(Sultana et al., 2012; Wang et al., 2012; Wright et al., 2012); and bars, free weights or machines are used to perform traditional anaerobic-type STe (Bloomer 2005; De Sousa et al., 2012; Mukaimoto and Ohno, 2012; Scott et al., 2011). A relevant aspect to be considered is how to match the load and intensity between STe and Ee, respectively.

With respect to Ee, a percentage of the maximum or reserve heart rate or $\mathrm{VO}_{2 \max }$ is typically used to determine intensity. Traditional

\footnotetext{
1 - Sport Sciences Department, University of Trás-os-Montes e Alto Douro, Vila Real Portugal.

2 - Research Center in Sports Sciences, Health Sciences and Human Development, Vila Real Portugal.

3 - Exercise, Health and Sport Sciences, University of Southern Maine, Gorham, Maine.

4 - School of Physical Education and Sports, Rio de Janeiro Federal University, Rio de Janeiro, Brazil.
} 
STe use a relative percentage of a one repetition maximum (1RM) to define the load (Braun et al., 2005; Burleson et al., 1998; Crommett and Kinzey, 2004). In our view, pairing or matching $\% \mathrm{VO}_{2 \max }$ with \% 1RM does not guarantee the same physiological intensity between both types of exercise (Bloomer 2005; Steele et al., 2012). To be predominantly aerobic for example, rhythmic and continuous exercises that work a large muscle group should be performed with an intensity at, but not above, the accumulation of $4 \mathrm{mmol} / \mathrm{l}$ blood lactate, and/or corresponding to the ventilatory threshold (Mukaimoto and Ohno, 2012); this is not at all ensured by using a percentage of $1 \mathrm{RM}$. Thus, we hypothesised that the higher values of $\mathrm{VO}_{2}$ during, and lower after, Ee as compared to traditional STe, were due to the variables defining the intensity or load and not the type of devices used.

The aim of the present study was to compare $\mathrm{VO}_{2}$ rates during and after predominantly aerobic exercises performed on ergometers and traditional STe that were matched using the threshold concepts of ventilation $\left(\mathrm{VE} / \mathrm{VCO}_{2}\right)$ and $4 \mathrm{mmol}$ onset of blood lactate accumulation, respectively. The duration of each exercise period was 30 minutes.

\section{Material and Methods}

To investigate the effect of STe and Ee on $\mathrm{VO}_{2}$, heart rate (HR) and ventilation (VE) values, subjects attended the laboratory for 14 different sessions (Figure 1). These sessions were performed after a 2 week period of adaptation and familiarisation with the exercises and protocols of this study. Anthropometric measurements (body mass, height and skin folds) were performed during the $1^{\text {st }}$ session, followed by a 1RM test (bench press (BP) and half squat (HS), both with free weights); 1RM retests were completed during the $2^{\text {nd }}$ session.

From the $3^{\text {rd }}$ to the $10^{\text {th }}$ session, tests were randomly conducted for determining the load to be used in STe (BP and HS) with percentages of 5, 10,15 and $20 \%$ of $1 \mathrm{RM}$ to find the corresponding load at an accumulation of $4 \mathrm{mmol} / \mathrm{l}$ blood lactate.

In the $11^{\text {th }}$ session, tests were performed to determine the intensity ( $\sim 67 \%$ of $\mathrm{VO}_{2}$ peak) to be used in Ee for the lower limbs (LL; cycle ergometry) and the $12^{\text {th }}$ session was utilised for load testing of the upper limbs (UL; arm- cycle ergometry).

In the $13^{\text {th }}$ and $14^{\text {th }}$ sessions, the Ee and STe tests were randomly conducted, at the selected intensity and load (respectively), and the values of $\mathrm{VO}_{2}, \mathrm{HR}$ and $\mathrm{VE}$ were collected 30 minutes before, during and after 30 minutes of the exercise sessions.

From the $1^{\text {st }}$ to the $13^{\text {th }}$ session, the time interval between sessions was 72 hours and between the $13^{\text {th }}$ and the $14^{\text {th }}$ sessions, 7 days. All subjects performed all sessions at the same time of the day (between 8 am and 10:30 am). Subjects did not perform any strenuous physical activity within 72 hours prior to the testing sessions and did not ingest any supplements, caffeine, or drugs/medications during that time period. Duplicate meals were consumed in the 24 hours preceding the $13^{\text {th }}$ and $14^{\text {th }}$ sessions.

\section{Participants}

The sample size was estimated through the statistics software Gpower based on the error of estimation $\alpha$ by $5 \%$, the estimate of the effect size of $0.5, \beta$ power of $80 \%$ and the $95 \%$ confidence interval, which resulted in a minimum number of 8 individuals.

Eight active men (age $24 \pm 2.33$ years; body height $171.75 \pm 7.67 \mathrm{~cm}$; body mass $71.25 \pm$ $5.78 \mathrm{~kg}$; body fat (7 skin folds) (Jackson and Pollock, 1978) $7.05 \pm 1.62 \%$ ) completed all study procedures. All subjects included in the present study had been practising STe and Ee for at least 6 months with a minimum frequency of 3 times a week for STe and twice a week for Ee, regardless whether the modalities (ST and E) were performed during the same session or separately. Medical history and physical activity questionnaires were completed to verify whether there was any limitation that could prevent participation in the study (Anamnesis and Par-Q test) (American College of Sports Medicine, 2010). Subjects were then informed about study procedures, the possible risks and discomforts related to the experimental sessions, and then signed an informed consent form to participate. The study was conducted according to the Declaration of Helsinki and approved by the University of Trás-os-Montes and Alto Douro Research Ethics Committee (CE-013.0043).

\section{Maximal Strength Testing}

The protocol of the 1RM test has been previously described by Kraemer and Fry (1995) 
and was used in the present study for the performance of BP and HS exercises (Panatta Sport, Italy). Both exercises had high 1RM test re-test reliability (intraclass correlation coefficients): BP ICC $>0.96$; and HS ICC $>0.97$. To minimise possible error, the following strategies were adopted: (a) specific information on the procedures and execution of the exercise was presented to each subject before testing, (b) verbal encouragement was provided to the subject during the test to promote their best effort, (c) the same bar and weight disks were used in all sessions, and (d) the rate of movement was 30 repetitions per minute (60 beats/min: 1 second concentric, 1 second eccentric) controlled by a metronome (Korg MA-330, New York, USA).

\section{Oxygen Uptake Assessment}

A maximal cardiopulmonary exercise test was performed to determine peak $\mathrm{VO}_{2}$ following a continuous incremental protocol on an upper body (UL) and lower body (LL) ergometer (SCIFIT Pro II, Berkshire, UK). All the protocols and materials used in the present study had been described by Vilaça Alves et al. (2012). The portable gas analyser $\left(C O S M E D{ }^{\circledR} K 4 b^{2}\right.$, Roma, Italy) and the HR monitor (Wireless Double Electrode, Polar ${ }^{\circledR}$, Kempele, Finland) were calibrated before each test according to manufacturer instructions (Cosmed, 2001). The environmental conditions and materials/equipment used were the same for all sessions (before, during and after the exercises).

The ventilatory threshold for the Ee (UL and LL) was measured as the point from which the ventilatory equivalent or coefficient of carbon dioxide $\left(\mathrm{VE} / \mathrm{VCO}_{2}\right)$ increased exponentially (after the increased ventilatory equivalent of oxygen $\mathrm{VE} / \mathrm{VO}_{2}$ ).

\section{Blood Lactate Assessment}

In order to find the load that elicited a blood lactate concentration of $4 \mathrm{mmol} / \mathrm{l}$ for the STe, during the $13^{\text {th }}$ and $14^{\text {th }}$ sessions subjects remained at rest for 30 minutes in the same room where the measurement of a resting metabolic rate (RMR) was made prior to performing the exercises. Blood samples (25 microlitres of capillary blood) were collected from a finger tip before and immediately after the tests using a portable analyser: Accutrend ${ }^{\circledR}$ Plus (Roche Diagnostics GmbH, COBAS, Vokietija, Germany). The portable analyser was calibrated every session with blood lactate concentrations of 2, 4, 10, 15 and $30 \mathrm{mmol} / \mathrm{l}$ Lactate-Kontrollsel (140 LCQ, Berlin, Germany).

These sessions consisted of 4 minutes of $\mathrm{BP}$ and HS exercises with the intensities of 5,10 , 15 and $20 \%$ of $1 \mathrm{RM}$, performed at a rate of 60 beats/min: 1 second concentric, 1 second eccentric. The following formula was used to find the corresponding value of $4 \mathrm{mmol} / \mathrm{l}$ : load in STe $=(4$ $\mathrm{mmol} / \mathrm{l}$ - blood lactate concentration value immediately below the $4 \mathrm{mmol} / \mathrm{l}$ ) $\mathrm{x}$ (load corresponding to the blood lactate concentration above $4 \mathrm{mmol} / \mathrm{l}$ - load corresponding to the blood lactate concentration below $4 \mathrm{mmol} / \mathrm{l}$ ) / (blood lactate concentration value immediately above the $4 \mathrm{mmol} / \mathrm{l}$ - blood lactate concentration value immediately below the $4 \mathrm{mmol} / \mathrm{l})+$ blood lactate concentration value immediately above the 4 $\mathrm{mmol} / \mathrm{l}$.

\section{Resting Metabolic Rate Measurements}

Before the exercises in the $13^{\text {th }}$ and $14^{\text {th }}$ sessions, and after at least 12 hours of fasting, subjects were transported to the location of the tests by a member of the evaluation team. The subjects were then taken to a silent, low-light room, where they remained lying in a supine position with the back reclined on a marquise for 30 minutes, to evaluate oxygen uptake at rest. The RMR was calculated from the values of $\mathrm{VO}_{2}$ measured during the last 10 minutes spent at rest, with the subjects being continuously measured by the portable gas analyser $\mathrm{K}_{4} \mathrm{~b}^{2}$. Immediately after the exercise session, the subjects returned to the same room for recovery $\mathrm{VO}_{2}$ measurements for a 30 minute period.

\section{Exercise Protocols}

Ergometer exercise session (Ee). Subjects performed ergometer exercises at their individual ventilatory threshold intensity $\left(\mathrm{VE} / \mathrm{VCO}_{2}\right)$, alternating the LL and UL exercises until the completion of the 30 minute session; exercise periods lasted 50 seconds with a 10 seconds transfer time between LL and UL.

Strength training exercise session (STe). The subjects performed HS and BP exercises for 30 minutes, with a load corresponding to an individual's blood lactate accumulation of 4 $\mathrm{mmol} / \mathrm{l}$, altering HS and BP the same way as in Ee (50 seconds exercise, 10 seconds transition time).

Since the load corresponding to a blood lactate concentration of $4 \mathrm{mmol} / \mathrm{l}$ in HS exercise 
was relatively low, a wooden bar, with the same dimensions of the bar used to measure the 1RM (220 cm long; $25 \mathrm{~mm}$ in diameter), but only $2 \mathrm{~kg}$ in mass, was used. The STe were performed at a rate of 60 beats/min (1 second concentric, 1 second eccentric) until the end of the session and with exercise time (50 seconds) and transfer time (10 seconds) equal to Ee. In both sessions, the first exercise to be performed was LL.

\section{Statistical Analysis}

An analysis of the distribution type (Shapiro-Wilk test) was conducted and then sphericity was confirmed by means of the Mauchly's sphericity test. Subsequently, ANOVA univariate testing was applied to observe the existence of statistically significant differences between exercise sessions. An ANOVA for repeated measures with the model [7 moments $x 2$ exercise types] was used to assess the existence of statistically significant differences between the values of $\mathrm{RMR}$ and recovery $\mathrm{VO}_{2}$ values (with a Bonferroni post-hoc test). The level of significance was set at 0.05 . Values are presented as mean \pm $S D$.

\section{Results}

The values regarding the characteristics of the subjects within each exercise session are presented in Table 1.

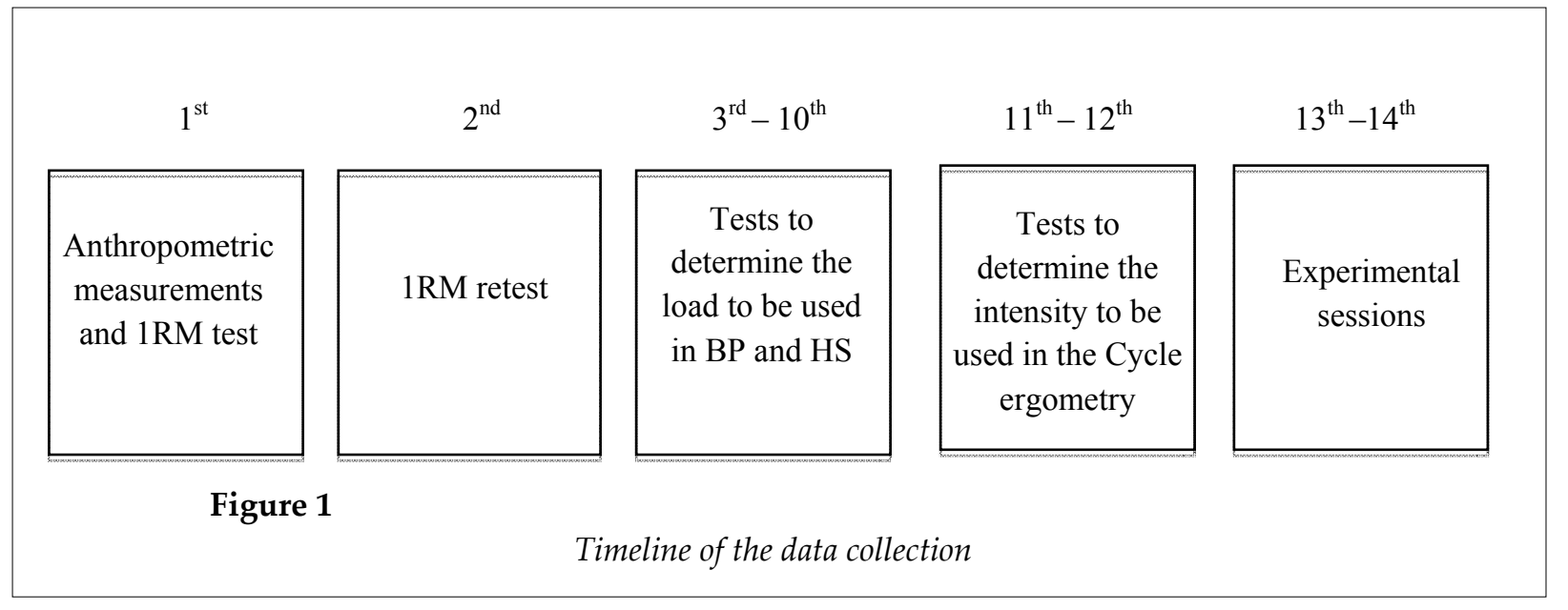

\begin{tabular}{|c|c|}
\hline Performance data collected on the first 12 sessions of the present study $(n=8)$ & $\begin{array}{c}\text { Table } \mathbf{1} \\
\text { e present study }(n=8)\end{array}$ \\
\hline Variables & Mean \pm SD \\
\hline 1RM Half Squat (kg) & $115.63 \pm 20.08$ \\
\hline 1RM Bench Press (kg) & $81.88 \pm 4.17$ \\
\hline Peak $\mathrm{VO}_{2}$ of Lower Limbs (ml/kg/min) & $42.99 \pm 4.52$ \\
\hline Peak $\mathrm{VO}_{2}$ of Upper Limbs (ml/kg/min) & $32.24 \pm 2.86$ \\
\hline Load of Half Squat 4 mmol/1 (kg) & $3.0 \pm 0.71$ \\
\hline Load of Bench Press 4 mmol/l (kg) & $10.5 \pm 2.82$ \\
\hline Ventilatory Threshold of Lower Limbs ( $\mathrm{ml} / \mathrm{kg} / \mathrm{min})$ & $28.58 \pm 3$ \\
\hline Ventilatory Threshold of Upper Limbs ( $\mathrm{ml} / \mathrm{kg} / \mathrm{min})$ & $21.79 \pm 1.88$ \\
\hline Load of Half Squat (\%1RM) & $2.70 \pm 0.88$ \\
\hline Load of Bench Press (\%1RM) & $12.83 \pm 3.35$ \\
\hline Ventilatory Threshold of Lower Limbs $\left(\% \mathrm{VO}_{2 \max }\right)$ & $66.53 \pm 2.5$ \\
\hline Ventilatory Threshold of Upper Limbs (\%VO $\left.{ }_{2 \max }\right)$ & $67.62 \pm 1.76$ \\
\hline
\end{tabular}


Table 2

Mean values and $S D$ of the $R M R$, absolute and relative $V_{2}$, Heart Rate, Ventilation, exercise and transition $\mathrm{VO}_{2}$ of session and divided for Limbs (Lower and Upper) during strength training exercises and ergometers exercises $(n=8)$.

\begin{tabular}{|c|c|c|}
\hline Variable & $\begin{array}{l}\text { STe session } \\
\text { Mean } \pm \text { SD }\end{array}$ & $\begin{array}{l}\text { Ee session } \\
\text { Mean } \pm \text { SD }\end{array}$ \\
\hline $\operatorname{RMR}(\mathrm{ml} / \mathrm{kg} / \mathrm{min})$ & $4.73 \pm 0.84$ & $4.57 \pm 0.5$ \\
\hline Absolute $\mathrm{VO}_{2}(1 / \mathrm{min})$ & $1.55 \pm 0.22$ & $1.77 \pm 0.23$ \\
\hline Relative $\mathrm{VO}_{2}(\mathrm{ml} / \mathrm{min} / \mathrm{kg}) *$ & $21.66 \pm 1.77$ & $24.96 \pm 3.6$ \\
\hline Ventilation (1/min) & $47.35 \pm 8.33$ & $55.48 \pm 8.2$ \\
\hline Heart Rate (bpm) & $118.34 \pm 16.07$ & $129.17 \pm 16.2$ \\
\hline Exercise $\mathrm{VO}_{2}(\mathrm{ml} / \mathrm{kg} / \mathrm{min}){ }^{*}$ & $22.05 \pm 1.61$ & $25.82 \pm 3.56$ \\
\hline Transition $\mathrm{VO}_{2}(\mathrm{ml} / \mathrm{kg} / \mathrm{min})$ & $21.59 \pm 2.19$ & $23.48 \pm 3.5$ \\
\hline Absolute $\mathrm{VO}_{2}$ of Lower Limbs (1/min) & $1.56 \pm 0.23$ & $1.81 \pm 0.25$ \\
\hline Absolute $\mathrm{VO}_{2}$ of Upper Limbs (1/min) & $1.54 \pm 0.22$ & $1.74 \pm 0.21$ \\
\hline Relative $\mathrm{VO}_{2}$ of Lower Limbs $(\mathrm{ml} / \mathrm{kg} / \mathrm{min})^{*}$ & $21.83 \pm 2.24$ & $25.44 \pm 3.84$ \\
\hline Relative $\mathrm{VO}_{2}$ of Upper Limbs $(\mathrm{ml} / \mathrm{kg} / \mathrm{min})^{*}$ & $21.54 \pm 1.73$ & $24.49 \pm 3.43$ \\
\hline Ventilation of Lower Limbs (1/min) & $49.01 \pm 8.19$ & $54.42 \pm 7.99$ \\
\hline Ventilation of Upper Limbs (1/min) * & $45.69 \pm 8.51$ & $56.5 \pm 8.49$ \\
\hline Heart Rate of Lower Limbs (bpm) & $120.87 \pm 13.69$ & $127.02 \pm 16.44$ \\
\hline Heart Rate of Upper Limbs (bpm) & $115.72 \pm 18.58$ & $131.15 \pm 15.94$ \\
\hline Exercise $\mathrm{VO}_{2}$ of Lower Limbs $(\mathrm{ml} / \mathrm{kg} / \mathrm{min}){ }^{*}$ & $22.44 \pm 2.09$ & $26.8 \pm 3.82$ \\
\hline Exercise $\mathrm{VO}_{2}$ of Upper Limbs $(\mathrm{ml} / \mathrm{kg} / \mathrm{min}){ }^{*}$ & $21.65 \pm 1.28$ & $24.84 \pm 3.33$ \\
\hline Transition $\mathrm{VO}_{2}$ of Lower Limbs (ml/kg/min) & $27.07 \pm 2.5$ & $24.29 \pm 3.22$ \\
\hline Transition $\mathrm{VO}_{2}$ of Upper Limbs $(\mathrm{ml} / \mathrm{kg} / \mathrm{min}){ }^{*}$ & $16.12 \pm 2.32$ & $22.68 \pm 3.84$ \\
\hline
\end{tabular}

* Significant difference between the Ste and eE groups ( $p<0.05) ; \mathrm{VO}_{2}-$ Oxygen Uptake

\section{Table 3}

Mean values and $\mathrm{SD}$ of relative $\mathrm{VO}_{2}$ and Ventilation divided into intervals of 10 minutes during strength training exercises and ergometers exercises $(n=8)$.

$\begin{array}{lll}\text { Variable } & \text { STe session } & \text { Ee session } \\ \text { Mean } \pm \text { SD } & \text { Mean } \pm \text { SD }\end{array}$

$\begin{array}{lcc}\mathrm{VO}_{2} \text { 0-10 } \mathrm{min}(\mathrm{ml} / \mathrm{kg} / \mathrm{min}){ }^{*} & 20.84 \pm 1.27 & 24.89 \pm 3.61 \\ \mathrm{VO}_{2} 10-20 \mathrm{~min}(\mathrm{ml} / \mathrm{kg} / \mathrm{min}) & * & 25.33 \pm 3.65 \\ \mathrm{VO}_{2} 20-30 \mathrm{~min}(\mathrm{ml} / \mathrm{kg} / \mathrm{min}) & 21.83 \pm 2 & 24.67 \pm 3.57 \\ \text { Ventilation } 0-10 \mathrm{~min}(\mathrm{l} / \mathrm{min}){ }^{*} & 22.31 \pm 2.25 & 54.5 \pm 8.73 \\ \text { Ventilation } 10-20 \mathrm{~min}(\mathrm{l} / \mathrm{min}) & 44.14 \pm 5.95 & 56.52 \pm 7.91 \\ \text { Ventilation } 20-30 \mathrm{~min}(\mathrm{l} / \mathrm{min}) & 48.32 \pm 9.07 & 55.55 \pm 8\end{array}$

* Significant difference between the STe and Ee groups $(p<0.05) ; \mathrm{VO}_{2}-$ Oxygen Uptake 


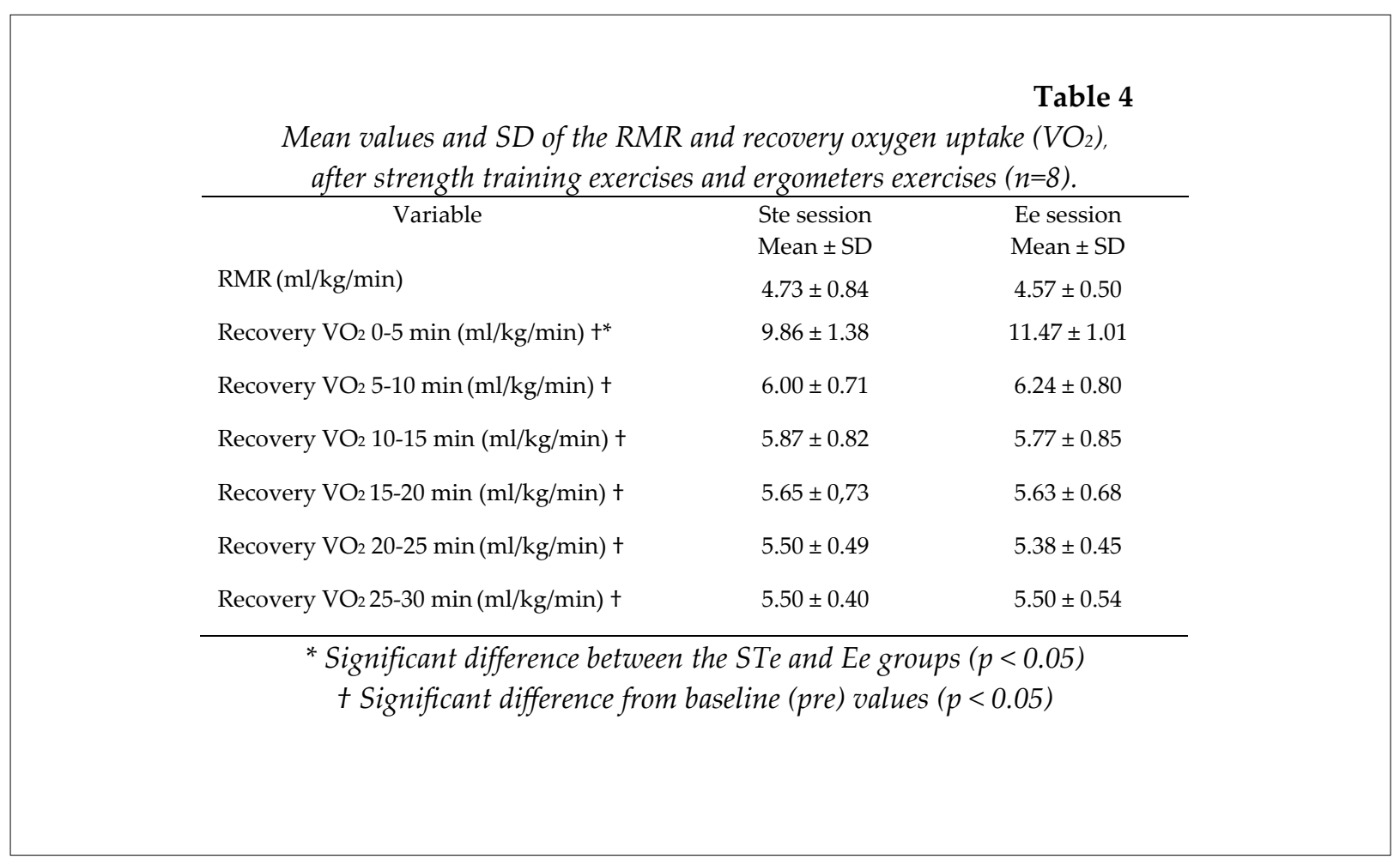

No significant differences were found between sessions, $(p>0.05)$, in the RMR, absolute $\mathrm{VO}_{2}, \mathrm{VE}, \mathrm{HR}$ and to transition $\mathrm{VO}_{2}$ (Table 2). However, average relative $\mathrm{VO}_{2}$ of the Ee session was significantly higher than that of the STe session ( $\left.F=5.444 ; p=0.035 ; \eta_{p}{ }^{2}=0.230\right)$ and average exercise $\mathrm{VO}_{2}$ was also significantly higher during Ee when compared to STe ( $\mathrm{F}=7.469 ; p=$ $\left.0.016 ; \eta_{p}{ }^{2}=0.348\right)$. Significantly higher average values in Ee compared to STe were also found regarding relative $\mathrm{VO}_{2}$ of $\mathrm{LL}(\mathrm{F}=5.267 ; p=0.038$; $\left.\eta_{\mathrm{p}^{2}}=0.273\right)$, relative $\mathrm{VO}_{2}$ of $\mathrm{UL}(\mathrm{F}=4.732 ; p=0.047$; $\left.\eta_{p^{2}}=0.253\right)$, VE of UL $\left(F=6.469 ; p=0.023 ; \eta_{p^{2}}=\right.$ 0.316), exercise $\mathrm{VO}_{2}$ of LL $\left(\mathrm{F}=8.020 ; p=0.013 ; \eta_{\mathrm{p}}{ }^{2}=\right.$ $0.364)$, exercise $\mathrm{VO}_{2}$ of $\mathrm{UL}\left(\mathrm{F}=6.374 ; p=0.024 ; \eta_{\mathrm{p}}{ }^{2}\right.$ $=0.313)$ and with transition $\mathrm{VO}_{2}$ of $\mathrm{UL}(\mathrm{F}=17.181$; $\left.p=0.001 ; \eta_{p}^{2}=0.551\right)$ (Table 2).

Regarding the Ee session, significantly higher values were observed compared to STe in relative $\mathrm{VO}_{2}$ from 0 to 10 minutes $(\mathrm{F}=8.955 ; p=$ $\left.0.010 ; \eta_{\mathrm{p}}{ }^{2}=0.390\right)$ and from 10 to 20 minutes $(\mathrm{F}=$ 5.636; $p=0.032 ; \eta^{2}=0.287$ ) as well as in VE from 0 to 10 minutes $\left(F=7.694 ; p=0.015 ; \eta_{p}{ }^{2}=0.355\right)$ (Table 3). Significant differences between exercise sessions were not found regarding relative $\mathrm{VO}_{2}$ from 20 to 30 minutes and VE from 10 to 20 and from 20 to 30 minutes (Table 3). Furthermore, there were no significant differences between sessions regarding the RMR and recovery $\mathrm{VO}_{2}$ (Table 4). However, significant differences were observed in the time effect $(\mathrm{F}=184.501 ; p<0.0001$; $\left.\eta_{\mathrm{p}}{ }^{2}=0.929\right)$ within the 2 sessions, namely the RMR which was significantly lower when compared to all the recovery moments $(p<0.05)$ (Table 4$)$, along with significant differences in the time effect $x$ session ( $\left.F=4.650 ; p=0.015 ; \eta_{p}{ }^{2}=0.249\right)$. Only recovery $\mathrm{VO}_{2}$ at 5 minutes revealed a significant difference between Ee and STe sessions (Table 4).

\section{Discussion}

We attempted to match the STe load with Ee intensity using the aerobic training concepts of ventilatory (for $\mathrm{Ee}$ ) and lactate (for STe) thresholds. Based on this methodology, the Ee ventilatory threshold (i.e., $\mathrm{VE} / \mathrm{VCO}_{2}$ ) for $\mathrm{UL}$ and LL was found at $66.5 \%$ and $67.6 \%$ of $\mathrm{VO}_{2 \max }$, respectively. Strength training at a $4 \mathrm{mmol}$ lactate threshold resulted in exercise loads of $12.8 \%$ and $2.7 \%$ of a 1-RM for the BP and HS, respectively. At these intensities and loads, subjects alternated UL and LL exercise periods (50 seconds) with transition periods (10 seconds) for both STe and $\mathrm{Ee}$, with a total exercise time of 30 minutes.

Under the conditions listed above, our 
findings regarding STe loads were markedly lower compared to those of other strength training studies in which lifting loads were predominantly based on the acquisition of strength (e.g., at $60 \%$ of $1 \mathrm{RM}$ for untrained and $80 \%$ of $1 \mathrm{RM}$ or higher for trained individuals) (Rhea et al., 2003). Viewed together, average relative $\mathrm{VO}_{2}\left(\mathrm{ml} \cdot \mathrm{kg} \cdot \mathrm{min}^{-1}\right)$ for Ee often slightly, though significantly, exceeded that of STe (Table 2). Yet, differences were not found after 20 minutes of exercise (Table 3). No significant differences were found with respect to absolute $\mathrm{VO}_{2}$ values $\left(\mathrm{ml} \cdot \mathrm{min}^{-1}\right)$. Moreover, HRs were often higher in Ee, although the differences were nonsignificant. We may therefore conclude that, although not matched perfectly, a similar threshold was somewhat achieved for Ee and STe (a $\mathrm{VE} / \mathrm{VCO}_{2}$ threshold may reflect a greater intensity as compared to a $4 \mathrm{mmol}$ blood lactate threshold (Meyer et al., 2005)).

Our research did not involve training per se, as only a single session was recorded to determine $\mathrm{VO}_{2}, \mathrm{HR}$ and VE responses for each condition. However, it appears that the concepts of aerobic training are met when selecting rather low lifting loads. That is, a $4 \mathrm{mmol}$ blood lactate concentration generated from $2.7 \%$ of $1 \mathrm{RM}$ for the HS and $12.8 \%$ of $1 \mathrm{RM}$ for the BP may have the potential to induce cardiovascular training effects over a 30 minute period (consisting of 15 minutes each of UL and LL work). Cardiovascular training adaptations have certainly been implicated with circuit resistance training modalities applying lifting loads of $40 \% 1 \mathrm{RM}$ providing a more wholebody type of conditioning (Gotshalk et al., 2004). Steele et al. (2012) further confirmed that lifting a weight to momentary muscular failure likewise improved cardiovascular variables. Thus, from an objective standpoint, a variety of resistance training modalities appear capable of achieving cardiorespiratory benefits. The STe loads used in our research are generally not thought to promote gains in strength, but resistance training guidelines have been reconsidered in terms of the unlikelihood of a single position statement for all (Carpinelli et al., 2004).

Post-exercise $\mathrm{VO}_{2}$ was significantly higher than the RMR at all times throughout recovery in both sessions, with significantly higher $\mathrm{VO}_{2}$ found only in Ee within the first 5 minutes of recovery (Table 4). The values of the present study concur with several studies indicating that recovery $\mathrm{VO}_{2}$ remained significantly higher than the RMR for at least 30 minutes after exercise (Drummond et al., 2005; Foureaux et al., 2006; Hackney et al., 2008; Schuenke et al., 2002). Volume and intensity are the variables that most influence post-exercise $\mathrm{VO}_{2}$ (Meirelles and Gomes, 2004), with the level of physical activity and gender of the subjects also influencing the magnitude and duration of the changes (Borsheim and Bahr, 2003; Warren et al., 2009). Braun et al. (2005) observed that circuit STe induced higher $\mathrm{VO}_{2}$ during the first 30 minutes of recovery compared to treadmill exercise, and there were no significant differences between 30 and 60 minutes after exercise. It is noteworthy that the Braun et al.'s (2005) study used different loads and sessions: the STe session was performed first and in a circuit format; and the Ee session was performed after, with an intensity matched to the STe session.

Our study was not without limitations. Although the sample size was small $(n=8)$ and the statistical power was not optimal $(80 \%)$, the repeated measures design appeared sufficient to analyse differences between STe and Ee sessions. Moreover, standardising exercise intensity between STe and Ee is quite problematic, not only because of likely physiological and metabolic differences between muscle contractions at $\% \mathrm{VO}_{2}$ versus $\% 1 \mathrm{RM}$, but also because as many as 25 lactate threshold concepts have been identified (Faude et al., 2009), as well as several gas exchange thresholds (Meyer et al., 2005); thus, our selection of a "threshold" may be subjective. However, this study can be the first step for future research to find the best way to control the intensity of aerobic exercise or strength exercise in order to make them comparable.

\section{Conclusion}

When exercise volume, intensity and loads were relativised in a predominantly aerobic (threshold) regime, the exercises performed with ergometers compared to traditional strength training exercises provoked somewhat similar responses, so that the load/intensity, and not the material/equipment used for the execution of an exercise, were variables that best influenced oxygen uptake. It can be concluded that strength exercises can also be used to improve oxygen uptake and cardiovascular fitness in the same way aerobic exercises do. 


\section{References}

American College of Sports Medicine (ACSM). ACSM's guidelines for exercise testing and prescription. Phildelphia: Wolters Kluwer - Lippincott Williams \& Wilkins; 2010

Bloomer RJ. Energy cost of moderate-duration resistance and aerobic exercise. J Strength Cond Res, 2005; 19: 878-882

Borsheim E, Bahr R. Effect of exercise intensity, duration and mode on post-exercise oxygen consumption. Sports Med, 2003; 33: 1037-1060

Braun WA, Hawthorne WE, Markofski MM. Acute EPOC response in women to circuit training and treadmill exercise of matched oxygen consumption. Eur J Appl Physiol, 2005; 94: 500-504

Burleson MA, O'Bryant HS, Stone MH, Collins MA, Triplett-McBride T. Effect of weight training exercise and treadmill exercise on post-exercise oxygen consumption. Med Sci Sport Exer, 1998; 30: 518-522

Carpinelli RN, Otto RM, Winett RA. A critical analysis of the ACSM position stand on resistance training: insufficient evidence to support recommended training protocols. JEPonline, 2004; 7: 1-60

Cosmed. K4b2 User manual. $7^{\text {th }}$ edition. Roma: Cosmed, 53-61; 2001

Crommett AD, Kinzey SJ. Excess postexercise oxygen consumption following acute aerobic and resistance exercise in women who are lean or obese. J Strength Cond Res, 2004; 18: 410-5

De Sousa NM, Magosso RF, Pereira GB, Souza MV, Vieira A, Marine DA, Perez SE, Baldissera V. Acute cardiorespiratory and metabolic responses during resistance exercise in the lactate threshold intensity. Int J Sports Med, 2012; 33: 108-113

Drummond MJ, Vehrs PR, Schaalje GB, Parcell AC. Aerobic and resistance exercise sequence affects excess postexercise oxygen consumption. J Strength Cond Res, 2005; 19: 332-337

Faude O, Kindermann W, Meyer T. Lactate threshold concepts: how valid are they? Sports Med, 2009; 39: 469490

Foureaux G, Pinto KC, Damasco A. Effects of excess post exercise oxygen consumption and resting metabolic rate in energy cost. Rev Bras Med Esporte, 2006; 12: 351-355

Gillette CA, Bullough RC, Melby CL. Postexercise energy expenditure in response to acute aerobic or resistive exercise. Int J Sport Nutr, 1994; 4: 347-360

Gotshalk LA, Berger RA, Kraemer WJ. Cardiovascular responses to a high-volume continuous circuit resistance training protocol. J Strength Cond Res, 2004; 18: 760-764

Hackney KJ, Engels HJ, Gretebeck RJ. Resting energy expenditure and delayed-onset muscle soreness after full-body resistance training with an eccentric concentration. J Strength Cond Res, 2008; 22: 1602-1609

Jackson AS, Pollock ML. Generalized equations for predicting body density of men. Brit J Nutr, 1978; 40: 497504

Kraemer W, Fry A. Strength testing; Development and evaluation of methodology. Physiological assessment of human fitness. Edited by Maud J, Foster C. Champaign Ill: Human Kinetics, 115-138; 1995

Meirelles CM, Gomes PS. Acute effects of resistance exercise on energy expenditure: revisiting the impact of the training variables. Rev Bras Med Esporte, 2004; 10: 131-138

Meyer T, Lucia A, Earnest CP, Kindermann W. A conceptual framework for performance diagnosis and training prescription from submaximal parameters - theory and application. Int J Sports Med, 2005; 26: 111

Mukaimoto T, Ohno M. Effects of circuit low-intensity resistance exercise with slow movement on oxygen consumption during and after exercise. J Sports Sci, 2012; 30: 79-90

Rhea MR, Alvar BA, Burkett LN, Ball SD. A meta-analysis to determine the dose response for strength development. Med Sci Sport Exer, 2003; 35: 456-464

Schuenke MD, Mikat RP, McBride JM. Effect of an acute period of resistance exercise on excess post-exercise oxygen consumption: implications for body mass management. Eur J Appl Physiol, 2002; 86: 411 - 417

Scott CB, Leighton BH, Ahearn KJ, McManus JJ. Aerobic, anaerobic, and excess postexercise oxygen consumption energy expenditure of muscular endurance and strength: 1-set of bench press to muscular 
fatigue. J Strength Cond Res, 2011; 25: 903-908

Steele J, Fisher J, McGuff D, Bruce-Low S, Smith D. Resistance training to momentary muscular failure improves cardiovascular fitness in humans: a review of acute physiological responses and chronic physiology adaptations. JEPonline, 2012; 15: 53-80

Sultana F, Abbiss CR, Louis J, Bernard T, Hausswirth C, Brisswalter J. Age-related changes in cardiorespiratory responses and muscular performance following an Olympic triathlon in well-trained triathletes. Eur J Appl Physiol, 2012; 112: 1549-1556

Vilaça Alves J, Saavedra F, Simão R, Novaes J, Rhea MR, Green D, Reis VM. Does aerobic and strength exercise sequence in the same session affect the oxygen uptake during and postexercise? J Strength Cond Res, 2012; 26: 1872-1878

Wang B, Tian Q, Zhang Z, Gong H. Comparisons of local and systemic aerobic fitness parameters between finswimmers with different athlete grade levels. Eur J Appl Physiol, 2012; 112: 567 - 578

Warren A, Howden EJ, Williams AD, Fell JW, Johnson NA. Postexercise fat oxidation: effect of exercise duration, intensity, and modality. Int J Sport Nutr Exerc Metab, 2009; 19: 607-623

Wright HE, Selkirk GA, Rhind SG, McLellan TM. Peripheral markers of central fatigue in trained and untrained during uncompensable heat stress. Eur J Appl Physiol, 2012; 112: 1047 - 1057

\section{Corresponding author:}

\section{José Vilaça - Alves}

Centro de Investigação em Desporto, Saúde e Desenvolvimento Humano

Universidade de Trás-os-Montes e Alto Douro

Edifício Ciências do Desporto - Quinta de Prados

5001-801 Vila Real - PORTUGAL

Phone: +351 259350000

Fax: +351 259350480

E-mail: josevilaca@utad.pt 